reciprocals which are required by users of calculating machines. There are three separate tables of circular functions having the arguments given respectively in degrees and decimals, in radians, and in degrees, minutes and seconds. An unusual feature is the provision of tables of the inverse circular and hyperbolic functions; these occur so frequently in numerical calculation that the provision of direct easily interpolated tables will go a long way towards easing the computor's lot.

The other main tables in Volume 2 are : exponential and hyperbolic functions, natural logarithms, the gudermannian and its inverse, the gamma function, and various forms of the probability integral. There is also a table for converting from rectangular to polar co-ordinates. Minor tables which might be noted give factors of numbers up to 3,400 and primes up to 12,919. All the necessary auxiliary tables required for interpolation are given.

The explanations which are prefixed to both volumes are masterpieces of lucid style and offer much wise advice to the computor. The same applies to the annotated tables, given in volume 2 , of formulæ for numerical integration and differentiation, and for the numerical solution of differential equations. The whole of Dr. Comrie's wide experience of numerical calculation has gone into the preparation and production of these volumes, and they are likely to become the standard tables for general use in work where more than four-figure accuracy is required.

Vi. V. WILKES<smiles>[CH]=C</smiles>

\section{THE LABOURER AND HIS HIRE}

\section{The Technique of Industrial Labour Payment}

Setting forth the Fundamental Principles of Time Study and Payment by Result. By C. L. Guest. Pp. xii + 198. (London: Macdonald and Evans, 1948.) 35s, net.

$\mathrm{N}$ reviewing a $60 \mathrm{k}$ dealing with a narrow applica. tion of $m$ phagement technique such as time study, the revl wer fis faced with a difficult choice. Should he, Mdge the contents against the standard required to atisf an experienced time-study engineer, or merely give a résumé of the subject-matter which may help students to decide whether the book contains subjects of interest to them ? This book by Nir. C. L. Guest makes the choice even more difficult, for it may be of interest to both types of reader. I have therefore made a personal choice and reviewed the book against my own standard of what a book with this title should contain.

The book sets out the technique of operation-time measurement, outlines methods of payment by result, and details the routines required for the application and maintenance of incentive systems. The section dealing with time study is concerned primarily with the detailed technique, and describes stop watches, study boards, study sheets, and the working up of results. One chapter is devoted to labour and machine utilization and one to motion study. The second section of the book deals with the various methods of applying standard times to wages as a basis for payment by results, these methods being discussed and compared. The title of the last section, namely, "Applying and maintaining a payment by results system", is misleading, for it also covers subjects such as production planning and labour engagement, in addition to subjects related to the title.

The book adds little to the existing body of knowledge of time study or payment by results, and, in spite of the sub-title which states that it sets forth fundamental principles, seems to set forth only the detailed techniques which the author has used. While these seem perfectly sound, they are not principles and can be applied only in particular circumstances. For this reason, the book must be read with circumspection by beginners. The trained time-study engineer will already know the techniques set out and will gain little from the first and second sections. The third section will help time-study men who wish to gain knowledge of wage-calculation methods.

Many detailed examples are given to support the text, and results are presented graphically. These pages of detailed figures hinder rather than help the student in reading the book, and certainly do not assist in teaching principles. They may also irritate the reader who has to wade through this mass in order to get to the next part of the text, and as a result distract his attention from more useful data which follow. If these pages of figures had to be included, they would have been far better placed in an appendix where the reader with both time and patience could have read them at leisure. Graphical presentation of results of time studies and the use of mathematically correct curves is a dangerous habit, for the uncontrollable variables in work content make their validity problematical. In addition, this method may create the unfortunate impression that time study is an exact science by which the work output of human beings can be measured precisely.

The section dealing with methods of payment could well have been deleted, for every text-book on this subject in the last twenty years seems to have described the Halsey and Rowan methods and compared these with the straight piecework method. In addition, most industrial engineers agree that the Halsey and Rowan systems are outmoded and no longer capable of application. The only possible methods of payment by results which can be applied successfully are the allowed-time and straight piecework methods with a guaranteed minimum rate. Discussion of these other methods is then valueless except when studying the history of payment by results.

The author could well have devoted more space to effort rating, a subject which has not yet been adequately covered. It seems that he is also recommending the introduction of yet another standard for rating, this time with a base of forty. Surely there is enough confusion already caused by the use of two bases, the hundred and sixty, without introducing yet a third which has even less to recommend it. Again, surely the author does not seriously recommend the use of the three-watch study board shown on page II. Labour relations are usually strained enough on the introduction of time study, without having them made worse by the use of such a formidable instrument.

This book failed to satisfy me, despite its wealth of detail and evidence of careful layout, because it is too involved for the student and too indefinite for the expert. It could be a useful addition to a selected list of text-books for managers and supervisors for reading, after the principles of labour payment had been established and examplestof practical application were needed.
R. J. Fraser 